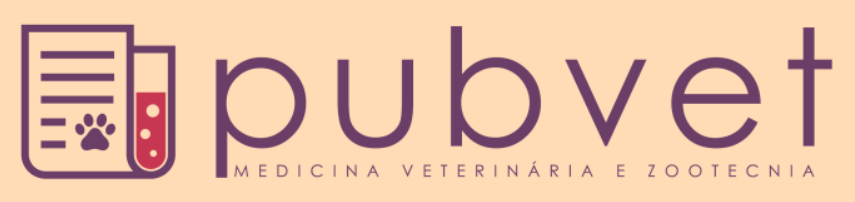

https://doi.org/10.31533/pubvet.v12n8a149.1-6

\title{
Atividade antitumoral da folha da Hymenaea martiana hayne em células mamárias de cães
}

\author{
Dielson da Silva Vieira ${ }^{1^{*}}$, Jusciene Bagagi Moura ${ }^{2} \bullet$, Felipe Eduardo Scardovelli da \\ Silva $^{1 \oplus}$, Fábio Taniwaki ${ }^{3}{ }^{\ominus}$, Tereza Cristina $\operatorname{Cardoso}^{1 \oplus}$ \\ ${ }^{1}$ Universidade Estadual Paulista, UNESP, Araçatuba, São Paulo, Brasil. \\ ${ }^{2}$ Campus III da Universidade Estadual da Bahia, UNEB, Juazeiro, Bahia, Brasil. \\ ${ }^{3}$ Universidade Estadual Paulista, UNESP, Botucatu, São Paulo, Brasil. \\ *Autor para correspondência, E-mail: dielson.vieira@ig.com.br
}

\begin{abstract}
RESUMO. As neoplasias da glândula mamária em cães são uma grande causa de morte em caninos devido às limitações de tratamento e a complexidade dos procedimentos cirúrgicos. Necessitando-se então de novas alternativas, como o extrato etanólico bruto da folha da $H$. martiana, que possui atividade antimicrobiana, anti-inflamatória e cicatrizante comprovada. Contudo, pouco se sabe sobre seus efeitos antitumorais e primordialmente, em células tumorais caninas. O objetivo do estudo foi avaliar o efeito antitumoral e citopático do extrato etanólico bruto da folha da $H$. martiana Hayne em células tumorais de cães e células VERO. Neste estudo, obtivemos uma ação do extrato frente as células tumorais a medida que aumentava a concentração do extrato, além disso, foram vistas alterações macroscópicas como formação de vacúolos, condensação do núcleo e formação de agredados celulares. Ao ser realizado o teste de MTT a função mitocondrial diminuiu à medida que aumentava a concentração do fitoterápico $(\mathrm{P}<0,05)$. Desta forma, a $H$. martiana Hayne pode ser pensada como uma alternativa, pois seus componentes bioativos demonstraram-se eficientes frente a células tumorais.
\end{abstract}

Palavras chave: AF-72, antitumoral, folhas, fitoterapia, terapêutica

\section{Antitumor activity of Hymenaea martiana hayne leaf in mammary cells of dogs}

\begin{abstract}
Neoplasms of the mammary gland in dogs are a major cause of death in canines due to treatment limitations and the complexity of surgical procedures. Therefore, new alternatives are needed, such as the crude ethanolic extract from the $H$. martiana leaf, which has antimicrobial, anti-inflammatory and cicatrizant activity. However, little is known about its antitumor effects and primarily on canine tumor cells. The objective of the study was to evaluate the antitumor and cytopathic effect of the crude ethanolic extract of the H. martiana Hayne leaf on dog tumor cells and VERO cells. In this study, we obtained an action of the extract in front of the tumor cells as the concentration of the extract increased. In addition, macroscopic alterations were seen, such as vacuoles formation, nucleus condensation and cell formation. When the MTT test was performed, mitochondrial function decreased as the phytotherapeutic concentration increased $(\mathrm{P}<0.05)$. Thus, $H$. martiana Hayne can be thought of as an alternative because its bioactive components have been shown to be efficient against tumor cells.
\end{abstract}

Keywords: AF-72, antitumor, leaves, phytotherapy, therapy 


\title{
Actividad antitumoral de la hoja de Hymenaea martiana hayne en las células de los perros de los perros
}

\begin{abstract}
RESUMEN. Las neoplasias de la glándula mamaria en perros son comúnmente la causa de muerte en caninos debido a las limitaciones de tratamiento y la complejidad de los procedimientos quirúrgicos. Se necesita entonces de nuevas alternativas, como el extracto etanólico bruto de la hoja de la $H$. martiana, que posee actividad antimicrobiana, antiinflamatoria y cicatrizante comprobada. Sin embargo, poco se sabe sobre sus efectos antitumorales y primordialmente, en células tumorales caninas. El objetivo del estudio fue evaluar el efecto antitumoral y citopático del extracto etanólico bruto de la hoja de la $H$. martiana Hayne en células tumorales de perros y células VERO. En este estudio, obtuvimos una acción del extracto frente a las células tumorales a medida que aumentaba la concentración del extracto, además, se observaron alteraciones macroscópicas como formación de vacuolos, condensación del núcleo y formación de agregados celulares. Al realizar la prueba de MTT la función mitocondrial disminuyó a medida que aumentaba la concentración del fitoterápico $(\mathrm{P}<0,05)$. De esta forma, la $H$. martiana Hayne puede ser pensada como una alternativa, pues sus componentes bioactivos se demostraron eficientes frente a células tumorales.
\end{abstract}

Palabras clave: AF-72, antitumoral, hojas, fitoterapia, terapéutica

\section{Introdução}

As neoplasias em cães se tornaram comuns com os grandes avanços na medicina veterinária. A prevalência de câncer em animais de estimação aumentou nas últimas décadas, tornando esta uma das principais causas de mortes em animais (Abdoon et al., 2016). Dentre as neoplasias, os tumores mamários caninos estão entre as neoplasias que mais ocorrem nas fêmeas, cerca de 250 casos numa população de 100.000 cães, sendo cerca de $70 \%$ de neoplasias malignas (Vascellari et al., 2016).

As doenças da glândula mamária em pequenos animais são de grande preocupação devido ao rápido desenvolvimento e prejuizo para o animal, além de afetar diretamente a relação homem/animal. O manejo clínico desta doença neoplásica é complicado, pois excluindo a cirurgia, há poucas opções terapêuticas eficazes (Queiroga et al., 2010).

As células cancerígenas por vezes podem desenvolver um padrão de resistência aos medicamentos prontamente utilizados, dificultando o tratamento, além disso, quase todos os agentes anticâncer têm efeitos secundários adversos em tecidos e órgãos (Abdoon et al., 2016). Desta forma, a busca de novos modelos e produtos para o tratamento do câncer mamário em caninos e felinos é de grande importância para pesquisadores e para clínicos.

O consumo de flavonóides está relacionado com a prevenção de doenças cardiovasculares e câncer, devido a seu potencial antioxidante e protetor (Putignani et al., 2013). A Hymenaea stigonocarpa possiu atividade antioxidante, devido a presença de taninos e flavonóides na sua casca e frutos (Orsi et al., 2014). Diante dos potenciais terapêuticos dos extratos de plantas do gênero Hymenaea, a atividade antitumoral não está elucidada, as plantas deste gênero estão presentes no território brasileiro e sua utilização deve ser considerada na medicina veterinária. Nesse estudo avaliamos o perfil citopático e antitumoral do extrato etanolico bruto (EEB) da folha da Hymenaea martiana em células AF-72 e células VERO, elucidando mais sobre a atividade da $H$. martiana na perspectiva do tratamento de câncer em animais.

\section{Material e Métodos}

Cultivo celular: A linhagem de células AF-72 (adenofibrossarcoma canino, ATCC® CRL1542) e a linhagem de células VERO (African Green Monkey Kidney cell), foram cultivadas em placas de cultura de fundo chato de 6 poços em meio Eagle modificado por Dulbecco (DMEM), suplementado com $10 \%$ de soro fetal bovino, penicilina $(100 \mu \mathrm{g} / \mathrm{mL})$ e estreptomicina $(100 \mu \mathrm{g} / \mathrm{mL})$. As células foram incubadas a $37^{\circ} \mathrm{C}$ com $5 \%$ de $\mathrm{CO}_{2}$ e $95 \%$ de $\mathrm{O}_{2}$ por $24 \mathrm{~h}$. O crescimento das células foi visualizado e acompanhado em microscópio invertido até atingir a confluência $\left(2 \times 10^{6}\right.$ células).

Ensaio experimental: Para a avaliação do efeito do extrato nas linhagens celulares o extrato 
etanólico bruto da Hymenaea martiana Hayne foi diluído na concentração estoque de $25.000 \mu \mathrm{g} / \mathrm{mL}$ até a diluição de $97,65 \mu \mathrm{g} / \mathrm{mL}$, sendo então utilizado neste estudo nove diluições em duplicata. As células após crescimento na concentração $2 \times 10^{6}$ células, tiveram o meio DMEM retirado, e então foi adicionado na placa $100 \mu \mathrm{L}$ do extrato e este ficou em contato com as células por 5 minutos, depois foi adicionado $1 \mathrm{~mL}$ do DMEM e as placas retornaram para estufa para incubação a $37{ }^{\circ} \mathrm{C}$ com $5 \%$ de $\mathrm{CO}_{2}$ e $95 \%$ de $\mathrm{O}_{2}$ por $24 \mathrm{~h}$. Para cada grupo celular foi feito um controle sem o acréscimo do extrato e a avaliação das células foi visualizada em microscópio invertido para observação do efeito do extrato diante das linhagens celulares.

Avaliação da função mitocondrial pela redução do MTT: A atividade das desidrogenases mitocondriais foi avaliada através do teste do brometo de 3-(4,5-dimetiltiazol-2-il)2,5-difenitetrazólio (MTT) segundo Hansen et al. (1989). O princípio do teste consiste na capacidade das desidrogenases mitocondriais de células vivas em converter o MTT em cristais de formazan de cor violácea. As células que foram cultivadas em placas de 6 poços e expostas aos extratos por 24 horas, tiveram após este período, a remoção do meio de cultura e adição aos poços de $100 \mu \mathrm{L}$ de solução de MTT diluído em água ultrapura. Após três horas de incubação em estufa a $37{ }^{\circ} \mathrm{C}$ e $5 \%$ de $\mathrm{CO}_{2}$, foram adicionados $900 \mu \mathrm{L} /$ poço de um tampão de lise, como indicado no KIT MTT Assay da Termofisher®. A porcentagem de células sobreviventes foi avaliada com base no controle (sem tratamento) e foi calculado e plotado de acordo com as concentrações do extrato.

Análise dos dados: Foi realizada a técnica de estatística descritiva das imagens para os achados macroscópicos dos grupos celulares. Para avaliação dos resultados do MTT, foi determinado o padrão de normalidade dos dados pelo teste de Shapiro-wilk, e os valores de médios de atividade foram comparados pelo teste ANOVA sendo considerada a significância de 5\%.

\section{Resultados}

O extrato da Hymenaea martiana Hayne possui atividade antitumoral frente às células caninas (AF-72) e citopática em relação as células VERO. Na Figura 1 observa-se alterações nas células tumorais, como aumento do diâmetro celular, vacuolização das células e alteração visual da morfologia celular e formação de agregados celulares, desta forma evidenciando a atividade do extrato em relação ao controle $(\mathrm{P}<0,05)$. Na Figura 2, as células VERO também sofreram alterações significativas quando comparadas com o controle $(\mathrm{P}<0,05)$, podendo então ser uma linhagem celular de referência em estudos com produtos naturais.

Quando avaliada a função mitocondrial (teste de MTT), foi observado no seguinte estudo que a atividade mitocondrial nas duas células foi preservada à medida que diminuía a concentração do extrato sendo então significativo $(\mathrm{P}<0,05)$ como se observa nas Figuras 1 e 2 . A intensa atividade do extrato partiu da maior concentração $(25 \mathrm{mg} / \mathrm{mL})$ até a concentração de $781,25 \mu \mathrm{g} / \mathrm{mL}$, decaindo nas diluições seguintes até não haver mais efeito como foi observado nas diluições 8 e $9(193,3 \mu \mathrm{g} / \mathrm{mL}$ e $97,65 \mu \mathrm{g} / \mathrm{mL}$, respectivamente, de acorco com o que foi observado no teste de MTT $(\mathrm{P}<0,05)$ e nas figuras dos grupos celulares.

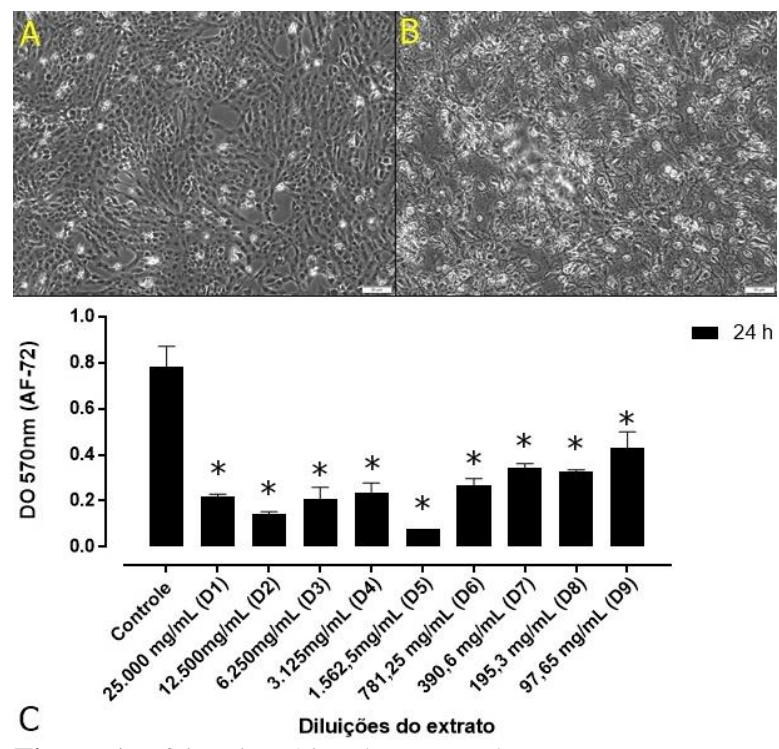

Figura 1. Efeito citopático do extrato da Hymenaea martiana Hayne em células AF-72. A: controle, B: diluição de $12.500 \mu \mathrm{g} / \mathrm{mL}, \mathrm{C}$ : Resultado do MTT $(\mathrm{P}<0,05)$. *: Indica $\mathrm{P}<0,05$ em relação ao controle.

\section{Discussão}

A atividade antitumoral e citopática da Hymenaea martiana Hayne foi determinada em células AF-72 e células VERO. As plantas do gênero Hymenaea já são utilizadas como produto medicinal para o tratamento de asma, pneumonia, gastrites e úlceras em humanos (Albuquerque et al., 2007). Evidenciando o importante papel dos fitoterápicos no tratamento e prevenção das doenças.

Como observado na Figura 1 , as células tumorais sofreram ação do extrato, e esta ação 
pode estar ligada aos componentes deste. Os fitoterápicos possuem vários compostos bioativos, que se diferenciam em termos de concentração na planta de acordo com o método de extração. $\mathrm{O}$ extrato casca da Hymenaea martiana Hayne, é rico em flavonóides, derivados antracênicos e naftoquinonas (Peixoto et al., 2015). Os compostos fenólicos são comumente encontrados em plantas comestíveis e não comestíveis, e eles têm sido relatados como tendo múltiplos efeitos biológicos, incluindo uma forte atividade antioxidante, que está ligada aos muitos efeitos farmacológicos dos compostos fenólicos (Sathyaprabha et al., 2011; Silva et al., 2012). Estes compostos são considerados metabólitos secundários que são sintetizados pelas plantas durante o seu desenvolvimento normal e em resposta a condições de infecção, ferimento e radiação UV, entre outros (Silva et al., 2012).
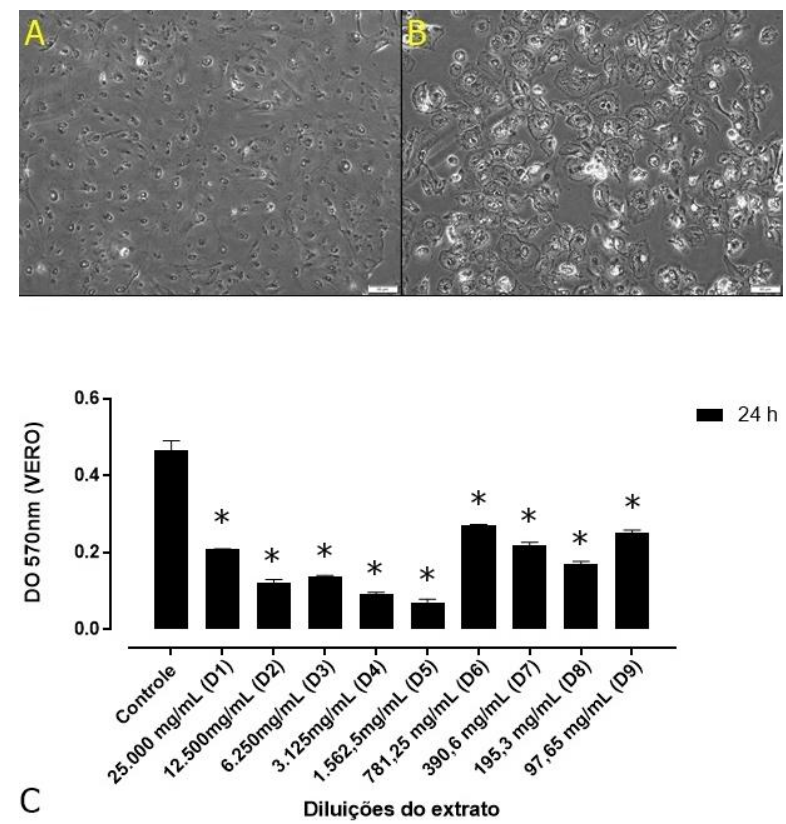

Figura 2. Efeito citopático do extrato da Hymenaea martiana Hayne em células VERO. A: controle, B: diluição de $12.500 \mu \mathrm{g} / \mathrm{mL}, \mathrm{C}$ : Resultado do MTT $(\mathrm{P}<0,05)$.*: Indica $\mathrm{P}<0,05$ em relação ao controle.

Nas células VERO, foram observadas alterações indicativas de atividade citopática, como vacuolização e formação de agregados celulares. Desta forma, a atividade tanto citopática quanto antitumoral da Hymenaea martiana Hayne, está ligada a função biológica de seus componentes bioativos, pois sabe-se que os flavonóides tendem a proteger as células VERO. No nosso trabalho as células tumorais sofreram ação do fitoterápico $(\mathrm{P}<0,05)$, este trabalho possui como diferencial a utilização do extrato derivado da folha da Hymenaea martiana, sendo que outros estudos utilizavam a casca e os frutos desta mesma planta. A atividade antitumoral pode estar relacionada à interação dos componentes presentes na planta. Como relatado por Vieira et al. (2018), o extrato da folha da Hymenaea martiana Hayne possui como constiutintes primordiais os flavonóides, porém isto não exclui que a ação nas linhagens celulares seja devido a outros componentes ainda não identificados.

No nosso estudo houve interferência morfológica e bioquímica $(\mathrm{P}<0,05)$ do extrato na atividade celular. Estudos similares avaliando toxicidade realizados com os extratos dos frutos de Morus nigra observaram que estes possuem uma ação protetora contra o dano peroxidativo de biomembranas e moléculas, isto pode ser atribuído a presença de flavonóides nesta planta, isolados também na sua casca do caule (Naderi et al., 2004; Wang et al., 2009). Assim como também, ao estudar o efeito tóxico das folhas da Abrus precatorius foram encontrados como constituintes primordiais monoterpenos, sendo que estes possuem um potencial quimioterápico, pois agem no metabolismo do mevalonato, suprimindo o desenvolvimento do câncer (Oladimeji et al., 2016). Podendo ser também uma alternativa futura no tratamento de câncer em animais. Alguns tipos de flavonóides são encontrados em plantas, um deles são as flavonas, que possuem como mecanismo de ação a inibição de bombas de efluxo em bactérias, resultado na indução da morte celular ou apoptose (Serpa et al., 2012). Outro tipo seria os flavonóis, sendo a quecertina um dos principais representantes deste grupo, já descrita como influente no tratamento de doenças crônicas e do câncer em humanos (Ranelletti et al., 2000; Spagnolo et al., 2012)

O ensaio com o MTT foi útil para avaliar o efeito do extrato nas linhagens celulares utilizadas. Tanto para a célula AF-72, quanto para a VERO, foi observada diferença estatística $(\mathrm{P}<0,05)$ em relação ao controle. Estes resultados do MTT confluem com o que foi visto macroscopicamente ao se avaliar a morfologia das células. Mesmo o extrato mostrando que também afetou as células VERO (Figura 2), isto não impede que o produto seja considerado para futuras funções anti-neoplásicas.

Indicamos que sejam realizados mais testes para avaliar a sensibilidade e a resposta ao extrato utilizado neste estudo, frente as linhagens utilizados e outros grupos celulares também. Pois foram encontrados efeitos nos dois grupos 
celulares, algo que era esperado somente nas células cancerígenas. Gonçalves et al. (2016) ao avaliarem o efeito antitumoral da 1, 4naftoquinona, comparou linhagens celulares com e sem câncer, obtendo ação citopática nas duas, porém estes autores destacam que estes dados podem ser de grande interesse para o desenvolvimento de uma nova droga antitumoral.

Nossa pesquisa foi a primeira a estudar o efeito do extrato da folha da $H$. martiana frente a células antitumorais caninas. Os efeitos citopáticos vistos no nosso ensaio mostraram alterações morfológicas que podem ser explicados devido a alterações de polaridade da membrana em ambas linhagens celulares, indicando talvez uma afinidade destas moléculas com a membrana de fosfolípidios, induzindo sua desorganização e conduzindo então para os efeitos observados (Hussein et al., 2013). Células cancerígenas possuem mais canais de cálcio do tipo L em sua membrana do que as células normais (Parkash \& Asotra, 2010). Indicando então a afinidade do extrato utilizado por estes canais, levando as alterações citopáticas. Existe uma grande preocupação para que seja feito um uso seguro e adequado das plantas medicinais principalmente quando se pretende utilizar os fitoterápicos por um período prolongado. Sendo necessário não só estudos farmacológicos para avaliação do potencial terapêutico das plantas como também a realização de estudos toxicológicos pré-clínicos e clínicos (Hussein et al., 2013; Gonçalves et al., $\underline{2016}$ ).

Sendo assim, as linhagens celulares foram encontradas danificadas ou mortas com anormalidades morfológicas evidentes nas células (Figuras 1 e 2). Indicando condensação do núcleo, formação de vacúolos, aumento do diâmetro celular, enrugamento da parede celular, sugerindo que seja um sinal de apoptose. Porém não se sabe de que forma o extrato agiu em cada linhagem e não foram estudados os receptores para os danos celulares que confirmem a ocorrência de apoptose. Esta diferença de atividade pode ser considerada devido à diferença de receptores da superfície celular (Salehi et al., 2016). Estes mesmos autores, discutem as diferentes formas que um produto antitumoral pode agir em distintos grupos celulares. Neste caso, destaca-se assim como relatado por Gonçalves et al. (2016), que mais estudos sejam aplicados afim de se elucidar a ação destes tipos de produtos para que sejam seguros e de forte eficácia.
Em conclusão, utilizando in vitro o Extrato Etanólico Bruto da folha da $H$. martiana Hayne observou-se que este possui efeitos citopáticos e antitumorais nas células do adenocarcinoma mamário canino, sendo possível pensar em mais estudos com aplicabilidade in vivo, com o intuito de se produzir um material terapêutico com potencial biotecnológico no combate as neoplasias em animais.

\section{Referências bibliográficas}

Abdoon, A. S., Al-Ashkar, E. A., Kandil, O. M., Shaban, A. M., Khaled, H. M., El Sayed, M. A. Shabaka, A. A. 2016. Efficacy and toxicity of plasmonic photothermal therapy (PPTT) using gold nanorods (GNRs) against mammary tumors in dogs and cats. Nanomedicine, 12, 2291-2297.

Albuquerque, U. P., Medeiros, P. M., Almeida, A. L. S., Monteiro, J. M., Neto, E. M. F. L., Melo, J. G. \& Santos, J. P. 2007. Medicinal plants of the caatinga (semi-arid) vegetation of $\mathrm{NE}$ Brazil: A quantitative approach. Journal of Ethnopharmacology, 114(3), 325-354.

Gonçalves, J. C. R., Coulidiati, T. H., Monteiro, A. L., De Carvalho-Gonçalves, L. C. T., De Oliveira Valença, W., De Oliveira, R. N. \& De Araújo, D. A. M. 2016. Antitumoral activity of novel 1, 4-naphthoquinone derivative involves L-type calcium channel activation in human colorectal cancer cell line. Journal of Applied Biomedicine, 14, 229-234.

Hansen, M. B., Nielsen, S. E. \& Berg, K. 1989. Re-examination, and further development of a precise and rapid dye method for measuring cell growth/cell kill. Journal of Immunological Methods, 119(2), 203-210.

Hussein, N., Lopes, C. C., Pernambuco Filho, P. C., Carneiro, B. R. \& Caseli, L. 2013. Surface chemistry and spectroscopy studies on 1,4naphthoquinone in cell membrane models using Langmuir monolayers. Journal of Colloid and Interface Science, 402, 300-306.

Naderi, G. A., Asgary, S., Sarraf-Zadegan, N., Oroojy, H. \& Afshin-Nya, F. 2004. Antioxidant activity of three extracts of Morus nigra. Phytotherapy Research, 18, 365-369.

Oladimeji, A. O., Babatunde, O., Rukayat, T. M., M'civer, F. A., Lawal, T. A. \& Ogunwande, I. A. 2016. GC-MS analysis and cytotoxic activity of essential oils from the leaves of Abrus precatorius L. Gaertn. Asian Pacific Journal of Tropical Disease, 6(5), 372-375. 
Orsi P. R., Seito, L.N. \& Di Stasi, L.C. 2014. Hymenaea stigonocarpa Mart. ex Hayne: A tropical medicinal plant with intestinal antiinflammatory activity in TNBS model of intestinal inflammation in rats. Journal of Ethnopharmacology, 151(1), 380-385.

Parkash, J. \& Asotra, K. 2010. Calcium wave signaling in câncer cells. Life Science, 87, $587-$ 595.

Peixoto, R. M., Araújo, R. M. P., Peixoto, L. J. S., Bomfim, S. A. G., Silva, T. M. G., Silva, T. M. S., Costa, M. M. 2015. Treatment of Goat Mastitis Experimentally Induced By Staphylococcus aureus A Formulation Containing Hymenaea martiana Extract. Small Ruminant Research, 130, 29-235.

Putignani, L., Massa, O. \& Alisi, A. 2013. Engineered Escherichia coli as new source of flavonoids and terpenoids. Food Research International, 54, 1084-1095.

Queiroga, F. L., Pires, I., Lobo, L. \& Lopes, C. S. 2010. The role of Cox-2 expression in the prognosis of dogs with malignant mammary tumours. Research in Veterinary Science, 88, 441-445.

Ranelletti, F. O., Maggiano, N., Serra, F. G., Ricci, R., Larocca, L. M., Lanza, P., ... Piantelli, M. 2000. Quercetin inhibits p21-ras expression in human colon cancer cell lines and in primary colorectal tumors. International Journal of Cancer, 85, 438-445.

Salehi, B., Bayat, M., Dezfulian, M. \& Sabokbar, A. 2016. The assessment of anti-tumoral activity of polysaccharide extracted from terrestrial filamentous fungus. Saudi Journal of Biological Sciences.

Sathyaprabha, G., Kumaravel, S. \& Panneerselvam, A. 2011. Analysis of antioxidant activity, total phenol, total flavonoid and screening of phytocomponents in Pleurotus platypus and Pleurotus eous. Journal of Chemical and Pharmaceutical Research, 3(6), 1-6.

Serpa, R., Franca, E. J., Furlaneto-Maia, L., Andrade, C. G., Diniz, A. \& Furlaneto, M. C.
2012. In vitro antifungal activity of the flavonoid baicalein against Candida species. Journal of Medical Microbiology, 61, 17041708.

Silva, M. E. G. S., Guimarães, A. L., Oliveira, A. P., Araújo, C. S., Siqueira Filho, J. A.; Fontana, A. P., ... Almeida, J. R. G. S. 2012. HPLCDAD analysis and antioxidant activity of Hymenaea martiana Hayne (Fabaceae). Journal of Chemical and Pharmaceutical Research, 4, 1160-1166.

Spagnolo, C., Russo, M., Bigotto, S., Tedesco, I., Laratta, B. \& Russo, G. L. 2012. Dietary polyphenolsin cancer prevention: the example of the flavonoid quercetin in leukemia. Annals of the New York Academy of Sciences, 1259, 95-103.

Vascellari, M., Capello, K., Carminato, A., Zanardello, C., Baioni, E. \& Mutinelli, F. 2016. Incidence of mammary tumors in the canine population living in the Veneto region (Northeastern Italy): Risk factors and similarities to human breast câncer. Preventive Veterinary Medicine, 126, 183-189.

Vieira, D. S., Peixoto, R. M., Costa, M. M., Freire, D. P., Silva, T. M. G. \& Silva, T. M. S. 2018. Atividade antimicrobiana in vitro do extrato etanólico bruto da folha da Hymenaea martiana Hayne frente à Staphylococcus spp. e avaliação de seu potencial como desinfetante em cabras. Pesquisa Veterinária Brasileira, 38, 462-469.

Wang, L., Gong, T. \& Chen, R. Y. 2009. Two new prenylflavonoids from Morus nigra L. Chinese Chemical Letters, 20, 1469-1471.

Recebido: 30 Mai. 2018.

Aprovado: 28 Jun.. 2018.

Publicado: 30 Jul. 2018.

Licenciamento: Este artigo é publicado na modalidade Acesso Aberto sob a licença Creative Commons Atribuição 4.0 (CC-BY 4.0), a qual permite uso irrestrito, distribuição, reprodução em qualquer meio, desde que o autor e a fonte sejam devidamente creditados. 